\title{
Neonatal symptoms in medium chain acyl coenzyme A dehydrogenase deficiency
}

\author{
Bridget Wilcken, Kevin H Carpenter, Judith Hammond
}

\begin{abstract}
Medium chain acyl coenzyme A dehydrogenase (MCAD) deficiency has not been thought to be associated with significant neonatal symptoms. To determine the validity of this, all known MCAD cases from New South Wales were reassessed. A total of 16 confirmed and three presumed cases has been identified in New South Wales, from 15 families. The casenotes of patients were reviewed, and where possible the mothers interviewed, either directly or by telephone, to obtain information about neonatal events. Six of the 16 confirmed cases had significant neonatal symptoms, with onset from 17 hours to 3 days of age. All required intravenous dextrose and four of the six needed other interventions, including hospital transfer. One baby died. All six were breast fed, but so were five of the eight asymptomatic neonates for whom information was available. Four of the six symptomatic neonates were homozygous for the common MCAD mutation, an $A$ to $G$ transition at position 985 , and one was heterozygous. It is concluded that serious neonatal symptoms are common in MCAD. Newborn siblings of MCAD cases must have careful monitoring and support during the first few days of life.

(Arch Dis Child 1993; 69: 292-294)
\end{abstract} Laboratory, NSW
The Children's Hospital and the Oliver Latham Health Department, Sydney, Australia Bridget Wilcken Kevin H Carpenter Judith Hammond

Correspondence to: Dr Bridget Wilcken, Oliver Latham Laboratory, NSW Health Department, PO Box 53, North Ryde (Sydney), NSW 2113, Australia.

Accepted 24 April 1993

Medium chain acyl coenzyme A dehydrogenase (MCAD) deficiency is the most commonly recorded disorder of fatty acid oxidation. ${ }^{1}$ It is characterised by episodes of fasting coma, associated with hypoketotic hypoglycaemia, raised plasma liver enzyme activities and blood urea and uric acid concentrations, and often mild hyperammonaemia. There is a distinctive organic aciduria with medium chain dicarboxylic aciduria together with excretion of acylglycines. Between episodes the patients are completely well. The episodes, often triggered by an intercurrent infection and resembling Reye's syndrome,

Table 1 Results of diagnostic tests in the MCAD patients with neonatal presentation

\begin{tabular}{|c|c|c|c|c|c|c|}
\hline \multirow{2}{*}{$\begin{array}{l}\text { Case } \\
\text { No }\end{array}$} & \multicolumn{4}{|c|}{ Reanalysed urinary acylglycines } & \multirow{2}{*}{$\begin{array}{l}\text { Phenylpropionate } \\
\text { loading test }\end{array}$} & \multirow{2}{*}{$\begin{array}{l}\text { Blood spot } \\
\text { DNA analysis }\end{array}$} \\
\hline & Hexanoylglycine & Suberylglycine & $P P G^{\star}$ & At age & & \\
\hline 1 & + & + & + & 7 years & Positive & G/G \\
\hline 2 & + & + & - & Neonatal & ND & $\mathrm{G} / \mathrm{G}$ \\
\hline 3 & + & + & - & 5 months & ND & $\mathrm{G} / \mathrm{G}$ \\
\hline 4 & + & + & - & Neonatal & Positive & G/A \\
\hline 5 & + & + & - & Neonatal & ND & $\mathrm{G} / \mathrm{G}$ \\
\hline 6 & + & + & + & 16 months & ND & $\mathrm{G} / \mathrm{G}$ \\
\hline
\end{tabular}

may, however, be lethal and approximately $25 \%$ of recorded cases have died, almost always during a first episode. However, some affected siblings of patients are known to remain healthy throughout childhood, never having any recognisable episodes. An A to $G$ transition at position 985 of the coding region of the MCAD gene has been identified as the most common mutation, occurring in $90 \%$ of MCAD genes. ${ }^{2}$

First episodes of illness appear typically between 4 months and 4 years of age, and have seldom been recorded outside these limits. No review mentions the possibility of neonatal symptoms. ${ }^{13-5}$ Among over 100 recorded cases only four papers describe apparent neonatal MCAD deficiency. In one, the clinical symptoms and biochemical findings in Japanese brothers are quite atypical ${ }^{6}$; MCAD has not been recorded in Japan, and the diagnosis in these brothers must be doubtful. In two other reports, however, the cases are well documented, ${ }^{78}$ and we recently described a boy who died on day 3 as a consequence of MCAD deficiency. ${ }^{9}$ This caused us to reappraise our 16 known and three presumed MCAD cases.

\section{Methods}

A history of the newborn period was obtained about our known MCAD patients, either by examination of hospital records or by direct questioning of parents. Urine samples that had been held frozen for up to 12 years at $-20^{\circ} \mathrm{C}$ were retrieved and organic acids including acylglycines reanalysed by gas chromatography-mass spectrometry of their trimethylsilyl derivatives after ethyl acetate/ether extraction. DNA analysis for the common MCAD mutation was performed on blood samples dried on filter paper (Dr S Forrest, Murdoch Institute, Melbourne). Phenylpropionate loading tests were carried out using the protocol of Seakins and Rumsby. ${ }^{10}$

\section{Results}

Six patients, described below, had had neonatal hypoglycaemia and other symptoms sufficiently severe to cause hospital transfer in two, to be considered life threatening in a further two, and fatal in the one already described. ${ }^{9}$ Eight had had no untoward neonatal symptoms and in two others reliable information was unavailable. Five of those eight children had been exclusively breast fed in the neonatal period and three had had bottle feeding. Table 1 shows the results of investigations that substantiated the diagnosis 
Table 2 Main clinical features in the neonatal MCAD cases

\begin{tabular}{|c|c|c|c|c|c|c|c|c|}
\hline $\begin{array}{l}\text { Case } \\
\text { No }\end{array}$ & Sex & $\begin{array}{l}\text { Birth } \\
\text { weight } \\
\text { (g) }\end{array}$ & Feeding & $\begin{array}{l}\text { Age at } \\
\text { onset }\end{array}$ & Clinical features & $\begin{array}{l}\text { Next } \\
\text { episode } \\
\text { (months) }\end{array}$ & $\begin{array}{l}\text { Present } \\
\text { age }\end{array}$ & Status \\
\hline 1 & $\mathrm{M}$ & 3700 & Breast & 24 hours & Lethargy, low blood glucose, hypotonia & 11 & 17 years & Well \\
\hline 2 & $\mathbf{M}$ & 3300 & Breast & 3 dayc & $\begin{array}{l}\text { Lethargy, low blood glucose, hypotonia, } \\
\text { vomiting }\end{array}$ & - & 11 years & Well \\
\hline 3 & $\mathbf{M}$ & 4444 & Breast + glucose & 24 hours & Lethargy, hypotonia, cardiac symptoms & 5 & 9 years & Well \\
\hline 4 & $\mathbf{M}$ & 3630 & Breast & 36 hours & Hypotonia, low blood glucose, seizures & - & 20 months & Well \\
\hline 5 & $\mathbf{M}$ & 3725 & Breast & 46 hours & $\begin{array}{l}\text { Lethargy, low blood glucose, hypotonia, } \\
\text { cardiac symptoms }\end{array}$ & - & - & Died \\
\hline 6 & $\mathrm{~F}$ & 3280 & Breast & 17 hours & Vomiting, low blood glucose & 15 & 18 months & Well \\
\hline
\end{tabular}

of MCAD deficiency in the six patients with neonatal symptoms, and table 2 summarises the pertinent points of their histories. Five of the six were homozygous for the common MCAD mutation, and one was heterozygous.

\section{Case reports}

CASE 1

A boy born in 1975, birth weight $3700 \mathrm{~g}$, was breast fed but fed poorly. At 24 hours he was lethargic, received tube feeds, and was transferred to the Children's Hospital, Sydney. Plasma glucose concentration was $1.4 \mathrm{mmol} / \mathrm{l}$. No metabolic studies were undertaken, and he improved over three days on intravenous dextrose. At 10 months, after three days of vomiting, he was hospitalised with hypoketotic hypoglycaemia, raised plasma hepatic enzymes and blood urea, and a dicarboxylic aciduria with suberylglycinuria, when a disorder of fatty acid oxidation was suspected, ${ }^{11}$ and later confirmed (see table 1). He had no further episodes and is well at 17 years.

CASE 2

A boy born in 1981, birth weight $3300 \mathrm{~g}$, Apgar scores of 5 and 9 at 1 and 5 minutes, fed poorly at the breast and became progressively more lethargic and hypotonic. On admission to the special care nursery his blood glucose concentration was $1.6 \mathrm{mmol} / \mathrm{l}$. There was a marked dicarboxylic aciduria. $\mathrm{He}$ was considered critically ill for three days and required intravenous dextrose at $8.3 \mathrm{mg} / \mathrm{kg} /$ minute. The diagnosis of MCAD deficiency was substantiated recently when he was 11 years old. $\mathrm{He}$ had been well in the interval.

CASE 3

A boy born in 1983, birth weight $4440 \mathrm{~g}$, had Apgar scores of 9 and 10 at 1 and 5 minutes. Breast feeds were complemented with oral glucose because of mild gestational glucose intolerance. At 24 hours he had rapid respirations, a systolic murmur and cardiomegaly, and was found to have a marked metabolic acidosis. He was transferred first to a regional hospital, where a very low blood glucose concentration was treated with a dextrose infusion, and then to the Children's Hospital, Sydney. Urinary organic acid analysis on day 5 showed slightly increased adipic and suberic acids. His symptoms settled over two days, and were considered to have been due to perinatal asphyxia. At 5 months he presented again, with hypoglycaemic fits, and a diagnosis of a fatty acid oxidation defect was made, later confirmed to be MCAD deficiency (table 1). No further episodes occurred and he is well at 9 years.

CASE 4

A boy was born in 1991, birth weight $3630 \mathrm{~g}$, with Apgar scores of 7 and 9 at 1 and 5 minutes. He was breast fed. At 36 hours he was floppy and pale, and had fits and opisthotonic posturing. He had a low reading on a glucose reagent strip and was treated with intravenous dextrose and anticonvulsants. No cause was found, but urine was obtained for metabolic screening and the organic acid profile was typical of MCAD deficiency. At 9 months, when well, his urinary excretion of the marker compounds hexanoylglycine and suberylglycine was increased. He remains well at 20 months.

CASE 5

A boy, born in 1991, birth weight $3725 \mathrm{~g}$, Apgar scores of 9 and 9 at 1 and 5 minutes, breast fed poorly on day 2 , became lethargic and hypotonic and had a low blood glucose concentration at 46 hours. He required intravenous glucose and inotropes, but suffered an acute cardiovascular collapse and died at 55 hours. ${ }^{9}$

\section{CASE 6}

A girl, birth weight $3280 \mathrm{~g}$, was born in 1991 after caesarean section (because of a previous section). She had Apgar scores of 9 and 9 at 1 and 5 minutes. She fed poorly on the breast and had vomiting and hypoglycaemia, with a blood glucose concentration of $1.6 \mathrm{mmol} / 1$ at 17 hours, requiring intravenous glucose for 24 hours. She represented at age 15 months with a Reye-like attack, and MCAD deficiency was diagnosed.

\section{Discussion}

No review of MCAD deficiency has mentioned neonatal presentation. ${ }^{13-5}$ Frequent feeding of young infants has been thought to protect MCAD deficient patients from episodes of fasting coma until the second half of the first year. The occurrence of significant symptoms in at least six of 16 patients from New South Wales, and the findings of other 'neonatal' cases in Australia (G Wilson, E Robertson, 
personal communication) makes it likely that such a presentation is not uncommon. Five of our six patients were homozygous for the common MCAD mutation, and so were apparently not suffering from an unusual form of MCAD deficiency. Certainly, neonatal presentation is the norm for one disorder of fatty acid oxidation, the severe form of glutaric aciduria type 2 (multiple acyl coenzyme A dehydrogenase deficiency), and is not uncommon in hydroxymethylglutaryl coenzyme A dehydrogenase deficiency. It also has been known to occur in almost all other fatty acid oxidation defects, with the exception of the carnitine uptake defect. $^{1}$

All of our symptomatic babies were breast fed. Breast fed infants may often be relatively starved during the first two to three days of life, and breast feeding could be a predisposing factor for neonatal symptoms in these. However, five of eight babies with MCAD who remained asymptomatic neonatally were also breast fed, so it is probable that breast feeding can be satisfactory for these infants. Nevertheless, asymptomatic babies are not necessarily normoglycaemic, and asymptomatic babies with MCAD deficiency could be at risk of hypoglycaemic brain damage in the first few days of life. When a sibling of a known MCAD patient is born, special precautions should be taken. These should include careful monitoring, and provision of supplementary feeds during the first few days of life, until breast feeding is securely established, or until MCAD deficiency has been excluded, if this can be done very promptly. In three of our patients, urine samples from the neonatal period were available for analysis, and these showed a typical organic acid profile, including increased concentrations of hexanoylglycine and suberylglycine (table 1). Such a profile has also been found in an asymptomatic neonate with $\mathrm{MCAD},{ }^{8}$ and while it is not yet certain that all asymptomatic MCAD patients can be readily identified by urinary acylglycine excretion, our symptomatic patients could readily have been so diagnosed. Increased phenylpropionylglycine was only seen in urine from older patients. This is not surprising as it is an intestinal bacterial product.

MCAD deficiency is likely to be underdiagnosed. With knowledge of the common mutation, the incidence of heterozygotes for MCAD deficiency in newborns has been studied. ${ }^{12}$ The predicted incidence of homozygotes with MCAD deficiency in Australia is about 1:15000-1:20000. At that incidence, we would expect on average four to six MCAD deficient babies to be born each year in New South Wales, but the numbers of known cases fall far short of this. Some MCAD patients certainly never become symptomatic but others may have life threatening symptoms. Those symptomatic in the neonatal period may be being overlooked.

The authors thank all those physicians who have been involved in the care of these children.

1 Roe CR, Coates PM. Acyl CoA dehydrogenase deficiencies. In: Scriver CR, Beaudet AI, Sly WS, Valle D, eds. The metabolic basis of inherited disease. 6th Ed. New York: metabolic basis of inherited diseas

2 Matsubara Y, Narisawa K, Tada K. Medium-chain acylCoA dehydrogenase deficiency: metabolic aspects. Eur $\mathcal{F}$ Pediatr 1992; 151: 154-9.

3 Stanley CA. Disorders of fatty acid oxidation. In: Fernandes J, Saudubray J-M, Tada K, eds. Inborn metabolic diseases. Berlin: Springer-Verlag, 1990: 395-410.

4 Touma EH, Charpentier C. Median chain acyl-CoA dehydrogenase deficiency. Arch Dis Child 1992; 67: 142-5.

5 Bennett MJ. The laboratory diagnosis of inborn errors of mitochondrial fatty acid oxidation. Ann Clin Biochem 1990; 27: 519-31.

6 Nobukuni Y, Yokoo T, Ohtani Y, et al. Neonatal onset of medium-chain acyl-CoA dehydrogenase deficiency in two siblings. Brain Dev 1988; 10: 129-34.

7 Catzeflis C, Bachmann C, Hale DE, et al. Early diagnosis and treatment of neonatal medium-chain acyl-CoA dehydrogenase deficiency: report of two siblings. Eur $\mathcal{F}$ Pediatr 1990; 149: 577-81.

8 Walker V, Mills GA, Weavind GP, Hall MA, Johnston PGB. Diagnosis of medium chain acyl-CoA dehydrogenase (MCAD) deficiency in an asymptomatic neonate. Ann Clin Biochem 1990; 27: 267-9.

9 Leung K-C, Hammond JW, Chabra S, Carpenter KH, Potter M, Wilcken B. A fatal neonatal case of mediumchain acyl-coenzyme A dehydrogenase deficiency with homozygous $A \rightarrow G^{985}$ transition. $\mathscr{f}$ Pediatr 1992; 121: homoz-8.

10 Seakins JWT, Rumsby G. The use of phenylpropionic acid as a loading test for medium-chain acyl-CoA dehydrogenase deficiency. $\mathcal{F}$ Inherited Metab Dis 1988; 11 (suppl 2): 221-4

11 Truscott RJW, Hick L, Pullin C, Halpem B, Wilcken B, Griffiths H. Dicarboxylic aciduria: the response to fasting. Clin Chim Acta 1979; 94: 31-4.

12 Matsubara Y, Narisawa K, Tada K, et al. Prevalence of $\mathrm{K} 329 \mathrm{E}$ mutation in medium-chain acyl-CoA dehydrogenase gene determined from Guthrie cards. Lancet 1991; 338: $552-3$. 